\title{
CENTROS DE INTERES TURISTICO NACIONAL Y NORMATIVA URBANISTICA: INFORME SOBRE UN CASO PRACTICO
}

\author{
POR \\ Manuel José Domingo Zaballos \\ Secretario de Administración Local de categoría superior. \\ Técnico urbanista
}

\begin{abstract}
ASUNTO
Estudio de detalle promovido por .... S. A., incidiendo en la manzana $H$ del Plan de Ordenación Urbana del Centro de Interés Turístico Nacional ... Alteración de términos municipales.
\end{abstract}

\section{INFORME JURIDICO}

El abajo firmante, Secretario del Consell Comarcal del ..., se complace en elevar a la consideración de esa Corporación el presente informe, requerido por acuerdo plenario del Ayuntamiento de ... en sesión de 20 de octubre del corriente año 1989. Interviene, debidamente autorizado por la Presidencia del Consell, prestando la asistencia jurídico-administrativa solicitada, en armonía con lo previsto en el artículo 33, a), de la Ley 6/1987, de 4 de abril, sobre Organización Comarcal de Cataluña.

\section{OBJETO DEL INFORME}

Instada al Ayuntamiento en fecha 7 de agosto por la mercantil ..., S. A., la aprobación de «Estudio de detalle de ordenación de la isla $\mathrm{H}$ de la urbanización ....), suscrito por el Arquitecto $\mathrm{D}$. ..., y habiéndose dejado sobre la mesa la resolución del asunto en sesión plenaria de 20 de agosto, corresponde al informante determinar fundadamente la adecuación o no de la solicitud al ordenamiento jurídico.

Se centrará el informante en estudiar la procedencia o improcedencia de aprobar el instrumento urbanístico presentado, excluyendo deliberadamente otro tipo de consideraciones, que pueden guardar relación con el asunto, pero que no son determinantes para la cabal resolución del concreto problema que ahora se acomete. 
No se le oculta a este letrado la peculiar y complejísima situación jurídica en que se encuentra la llamada urbanización ...; sin embargo, afrontar tal problemática integralmente -desde luego desde su vertiente estrictamente jurídico-administrativa- no debe ser necesariamente el objeto preciso de este primer informe, habida cuenta de que, según se motivará y concluirá, la respuesta sobre la procedencia o no de aprobar el Estudio de Detalle, es relativamente sencilla. Ello no es óbice para que, con posterioridad y con mayor detenimiento, se afronte por el informante la problemática jurídicoadministrativa integral de la urbanización ..., y se eleve a esa Corporación un nuevo informe tan exhaustivo como el asunto merece.

\section{NORMATIVA DE APLICACION}

Dada la singularidad del ordenamiento urbanístico, muchos y dispersos preceptos norman y guardan relación con los Estudios de Detalle, siendo de resaltar los siguientes:

- Artículo 47.2, i), de la Ley 7/1985, de 2 de abril, reguladora de las Bases de Régimen Local.

- Artículos 14; 35.1, e); 40.2 y 41 de la Ley del Suelo, texto refundido de 9 de abril de 1976.

- Artículos 65, 66 y 94.1 del Reglamento de Planeamiento Urbanístico, aprobado por Real Decreto 2159/1978, de 23 de junio.

- Artículos 4.1 y 2 del Real Decreto-ley 3/1980, de 14 de marzo, sobre creación del suelo y agilización de la gestión urbanística.

- Artículos 11 y 14 de la Ley 3/1984, de 9 de enero, de Medidas de Adecuación del Ordenamiento Urbanístico de Cataluña.

- Demás normativa concordante, así como la que se cita en los distitos apartado de este informe, incluida la Ley 197/1963, de 28 de diciembre, sobre Centros y Zonas de Interés Turístico Nacional, con su Reglamento ejecutivo de 28 de diciembre de 1964 (fundamentalmente el capítulo II de dicho Reglamento).

En cualquier caso, debe tenerse en cuenta el Decreto autonómico $143 / 1984$, de 10 de abril, por el que se aprueba la tabla de vigencias de disposiciones afectadas por la Ley 3/1984, de 9 de 
enero, así como la tabla de vigencias de las disposiciones afectadas por la Ley 19/1975, de 2 de mayo.

\section{NATURALEZA, FUNDAMENTO Y POSICION ORDINAMENTAL DEL ESTUDIO DE DETALLE}

En cuanto a esta controvertida figura, parte el informante (siguiendo a la mejor doctrina científica: García de Enterría, Parejo Alfonso, Laso Martínez, González Pérez, y a la más reciente jurisprudencia del Tribunal Supremo) de su auténtico carácter de instrumento de ordenación urbanística; los Estudios de Detalle son, en definitiva, planes municipales.

Es indudable, sin embargo, que no pueden ser considerados a la luz de la legislación precitada como planes independientes, sino meramente complementarios. Ya con anterioridad a su creación con carácter general en la reforma de la Ley del Suelo, operada por Ley de 2 de marzo de 1975, el Consejo de Estado, en dictamen de 22 de mayo de 1969 -y refiriéndose a la legislación específica de Madrid- asevera:

«... son, en definitiva, normas complementarias del Ordenamiento Urbanístico, que no lo contradicen y que vienen a complementarlo con relación a áreas geográficas o sectores donde tal necesidad se plantea con carácter más acusado».

El Estudio de Detalle, en palabras de Enterría-Parejo, es:

«...como un Plan -ubicado en el último escalón del subsistema de Planeamiento Municipal- derivado, ejecutivo, de carácter no necesario y de función complementaria de las determinaciones del Plan General en suelo urbano y del Plan Parcial en los restantes supuestos .... .

Tanto el artículo 14 de la Ley del Suelo como el 65.1 del Reglamento de Planeamiento corroboran la complementariedad y limitaciones de dicha figura. Así, por lo demás, se ha venido entendiendo por la jurisprudencia del Tribunal Supremo, que ha resaltado el último lugar o escalón que en el proceso de concreción de la ordenación urbanística cumplen los Estudios de Detalle. (A modo de ejemplo, sentencias del Tribunal Supremo de 26 de abril de 1985, 28 de enero de 1983 y 19 de julio de 1984).

De todo ello se infiere que el Estudio de Detalle necesita para su validez y operatividad de la previa habilitación por un Plan Urbanís- 
tico superior; un plan que haya clasificado previamente -respetando el mandato del artículo 78 de la Ley del Suelo- el suelo como urbano. Esa primera figura de Planeamiento no puede ser otra que un Plan General, unas Normas Subsidiarias de Planeamiento Municipal y-con algunas reservas- un Proyecto de Delimitación de Suelo Urbano. También puede ser un Plan Parcial, previa existencia de Plan General o Normas Subsidiarias de Planeamiento Municipal.

En cualquier caso, el Estudio de Detalle sólo merece operar en suelo urbano, incluyendo como tal el que ha adquirido formal $y$ materialmente tal carácter como consecuencia de la dinámica Plan General-Plan Parcial de desarrollo. Esta debe ser la cabal interpretación del artículo 14 de la Ley del Suelo y 65.1 del RP. Reiterando lo antedicho, con otras palabras: el ámbito superficial sobre el que puede desplegar su validez y eficacia un Estudio de Detalle únicamente puede ser dentro de suelo urbano, tanto si fuese originariamente clasificado por Plan General lo instrumento sustitutorio del mismo) o derivadamente por Plan Parcial.

\section{FUNDAMENTACION ESGRIMIDA POR EL ESTUDIO DE DETALLE PRESENTADO Y ANTECEDENTES}

El Estudio de Detalle de iniciativa particular presentado pretende fundamentarse, según se afirma en su apartado cuarto (p. 5) en el "Plan de Ordenación Urbana» aprobado a través del artículo segundo del Decreto 3426/1969, de 13 de noviembre, por el que se declaró Riomar Centro de Interés Turístico Nacional conforme a la Ley 197/1963, de 28 de diciembre, de Zonas y Centros de Interés Turístico Nacional.

Nos remitimos a lo antedicho al tratar del objeto de este infome, pero, en cualquier caso, forzoso resulta reseñar que, segregado parte del termino municipal de ... para constituir municipio independiente con el nombre hoy de .... Riomar pasó a ser parte del término de este nuevo municipio, en virtud del Decreto .../1977, por el que se acordó la precitada segregación. Así resulta que:

a) Desde entonces el único instrumento de Planeamiento para el nuevo municipio ha sido el Proyecto de Delimitación de Suelo Urbano de ..., aprobado por la Comisión Provincial de Urbanismo en sesión de 15 de octubre de 1980 («BOP» núm. 273, de 27 de noviembre).

b) En dicho proyecto figura fuera de la delimitación de suelo urbano el espacio físico sobre el que pretende operar el Estudio de Detalle presentado (zona IV de las comprendidas en el Plan de Ordenación del Centro de Interés Turístico Nacional). 
c) Si se contempla como suelo urbano en el indicado Proyecto de Delimitación de Suelo Urbano la llamada zona $V$, entonces -1980- y sobre todo hoy, consolidada por la edificación sobradamente en más de la mitad de su superficie y con los servicios a los que se refiere el artículo 81.2 de la Ley del Suelo, según queda acreditado en el expediente mediante los dictámenes técnicos pertinentes.

d) El Estudio de Detalle presentado parece obviar deliberadamente, aunque lo cite, el Proyecto de Delimitación del Suelo Urbano de 1980 centrándose siempre en lo que llama «Plan Parcial Rectificado» que no es otro que el Plan de Ordenación Urbana del Centro de Interés Turístico Nacional; aprobado por la Administración Central del Estado mediante el Decreto antedicho y al amparo de la normativa específica sobre Centros de Interés Turístico Nacional, incluyendo su peculiar procedimiento de redacción y aprobación. Dicho Plan, en modo alguno participa de la naturaleza de Plan Parcial, porque como tal nunca llegó a aprobarse y porque su contenido difiere del de los Planes Parciales, aunque aparentemente guarde similitud.

Se asegura por la peticionaria que el Plan no estableció plazos de ejecución de cada una de las etapas.

\section{ANALISIS Y CRITICA DE LA FUNDAMENTACION ALEGADA}

En este estado de cosas, cabe preguntarse si efectivamente tiene o no fundamento y soporte urbanístico superior el Estudio de Detalle que venimos estudiando. Tratando de responder a esta cuestión, trabajaremos con dos hipótesis sin -por el momentorechazar ninguna:

Primera. Entender que el Proyecto de Delimitación del Suelo Urbano de ..., aprobado en 1980, debe prevalecer $y$, por tanto, dejó sin validez el Plan de Ordenación Urbana del Centro de Interés Turístico Riomar, en el ámbito comprendido por las zonas no urbanizadas ni consolidadas por la edificación (todas excepto la V).

Esta hipótesis no es nada desdeñable, por lo siguiente:

En la fecha de aprobación del Proyecto de Delimitación del Suelo Urbano la base normativa de tal figura se encontraba exclusivamente en el artículo 81 del texto refundido de la Ley del Suelo de 9 de abril de 1976, en relación con su disposición transitoria quinta y en los artículos 101 a 103 del Reglamento de Planeamiento. Con independencia de cuál sea la posición sobre la 
naturaleza jurídica de estos PDSU, está claro en la legislación y en la jurisprudencia que su objeto es la fijación de los límites del suelo urbano y del no urbanizable, constatando la concurrencia o no de las circunstancias previstas en el artículo 81 de la Ley del Suelo, en cuanto se refiera a los municipios que carezcan de Plan General; este último suelo (el no urbanizable) se configura con carácter residual: todo terreno fuera del espacio o perímetro acotado como urbano es no urbanizable.

Es cierto que la Ley 197/1963, de 28 de diciembre, de Centros y Zonas de Interés Turístico Nacional, no ha sido expresamente derogada en su integridad ni por el legislador estatal, ni sustituida por el autonómico catalán y que además no se hizo uso de la autorización contenida en la disposición adicional tercera de la Ley de Reforma de 1975 para adaptar la Ley de Zonas y Centros de Interés Túrístico Nacional a la reforma de la Ley del Suelo, continuando, por tanto, vigente aquélla, salvo alguna derogación puntual operada, por ejemplo, mediante la Ley de Costas de 1988.

Sin embargo, en la tabla de vigencias de disposiciones afectadas por la Ley 19/1975, de 2 de mayo, de reforma de la Ley sobre Régimen del Suelo y Ordenación Urbana, se declara vigente dicha Ley de Centros y Zonas de Interés Turístico Nacional.

«... en lo que no se oponga al texto refundido de 9 de abril de 1976.»

y en la disposición transitoria primera, tanto de la Ley de Reforma como del texto refundido de la Ley del Suelo, se obliga a la adaptación de los Planes Generales de Ordenación vigentes, pudiendo limitarse tal adaptación.

«... a la clasificación del suelo, determinación del aprovechamiento medio e incorporación del programa pertinente.»

Podría perfectamente mantenerse que el Proyecto de Delimitación del Suelo Urbano del nuevo municipio de ..., con carácter transitorio, hasta que se apruebe el Plan General de Ordenación Urbana o las Normas Subsidiarias de Planeamiento Municipal, cumplió con el mandato legal de adaptación a la nueva Ley del Suelo de los Planes Generales; en este caso, del Plan General de Ordenación Urbana de ..., de fecha 17 de noviembre de 1964, que obviamente comprendía el espacio físico que luego configuró el término del nuevo municipio de ...

Ciertamente la disposición transitoria primera, tanto de la Ley 19/1975, de 2 de abril, como del subsiguiente texto refundido, 
parece indicar que la adaptación de los Planes Generales anteriores para acomodarlos a la reforma debía hacerse mediante otros Planes Generales, o mediante la revisión de los mismos; sin embargo, en nuestro caso, y como quiera que antes de vencer el plazo de cuatro años establecido en el apartado segundo de la citada disposición transitoria para proceder a la adaptación, se produjo la segregación de parte del término de ..., naciendo el municipio de ..., parece acorde con el espíritu y sentido de la Ley que la adaptación se acometiese momentáneamente por el más modesto instrumento urbanístico que es el Proyecto de Delimitación de Suelo Urbano.

Secunda esta argumentación la propia producción normativa posterior: El Real Decreto-ley 16/1981, de 16 de octubre (a pesar de su controvertida aplicabilidad directa en Cataluña, sobre lo que ahora no es momento de entrar), permitió en su artículo 1.3 que la adaptación de un Plan General anterior se produjese mediante normas subsidiarias municipales y sin perjuicio de la aplicación directa de los criterios contenidos en su artículo 2.1, para determinar qué suelos podrían participar de la naturaleza de urbanos, permitió a los Ayuntamientos, en el artículo 2.2:

«... aprobar la delimitación de la totalidad del suelo urbano de sus términos municipales, o por partes, antes de la adaptación de sus respectivos Planes Generales.»

Aprobado en 1980 el Proyecto de Delimitación del Suelo Urbano de ..., publicado el acuerdo reglamentariamente y no impugnado, desplegó sus efectos en cuanto a clasificación del suelo, haciendo "tabla rasa" de la situación preexistente.

Los propietarios y demás interesados -incluidos los ahora promotores del Estudio de Detalle- aceptaron implícitamente la delimitación de suelo urbano y la clasificación como no urbanizable de los terrenos fuera de su perímetro.

La sola incoación del expediente para la aprobación del Proyecto de Delimitación del Suelo Urbano ya partió de la concepción de que el nuevo municipio ... carecía de planeamiento urbanístico superior y precisamente por eso, una vez aprobado el Proyecto de Delimitación del Suelo Urbano, es este instrumento el que -lo reiteramos, transitoriamente, hasta la aprobación del Plan General o normas subsidiarias municipales- contempla los aspectos imprescindibles para la aplicación del ordenamiento urbanístico en el término municipal.

Pretender volver nueve años después de la aprobación del proyecto de Delimitación del Suelo Urbano a una ordenación anterior, puede resultar, por lo demás, contrario al principio de 
seguridad jurídica contenido en el artículo 9 de la Constitución Española. Esta reflexión no nos parece baladí, porque, generalizado el criterio de que en el término municipal de ...... sólo es urbano el suelo así delimitado en el Proyecto de 1980, han podido producirse transmisiones de la propiedad inmobiliaria en base -fundamentalmente en cuanto a su posible uso, y consecuentemente, en su precio- a la clasificación operada por el repetido PDSU; es más, probablemente se hayan producido precisamente sobre terrenos incluidos en el originario Plan de Ordenación de Riomar, luego excluidos de su carácter de urbanos por el PDSU (que únicamente contempla como suelo urbano la zona $V$ del viejo Plan de Ordenación de Riomar). Mantenerse ahora por el Ayuntamiento que dichos terrenos no fuesen afectados por la delimitación operada en 1980 . además de ir en contra de sus propios actos, podría suponer una actitud favorable a iniciativas privadas especuladoras, siendo dicha actitud difícilmente compatible con el mandato contenido en el artículo 47 de nuestra norma suprema, ordenando a los poderes públicos regular «la utilización del suelo de acuerdo con el interés general para impedir la especulación".

De acuerdo con esta primera hipótesis - prevalencia de la delimitación de 1980 sobre la ordenación anterior- el Estudio de Detalle presentado no puede ser aprobado, por la elemental razón de que opera sobre un espacio físico clasificado como suelo no urbanizable, sobre el que no caben Estudios de Detalle, según se cree haber demostrado en el apartado III de este informe.

Segunda. Manteniéndose la segunda de las hipótesis, el PDSU no pudo alterar el régimen urbanístico derivado del también reiterado "Plan de Ordenación Urbana" del Centro de Interés Turístico Nacional.

Efectivamente, no faltan motivos para aferrarse a esta concepción, que es la del Estudio de Detalle presentado, así como la del informe de Letrado acompañando a la solicitud.

A nuestro entender, son argumentos en favor de la segunda hipótesis:

- La Ley de 28 de diciembre de 1963 de Centros y Zonas de Interés Turístico Nacional no ha sido derogada y tampoco su Reglamento Ejecutivo, aprobado por Decreto de 23 de diciembre de 1964, reconociendo la disposición final tercera de la Ley de 2 de mayo de 1975, que entre tanto no se adapten las normas de dicha Ley de 1963 a las de la nueva Ley del Suelo, continuará vigente en todos sus términos aquélla.

- El Plan de Ordenación Urbana del Centro de Interés Turístico Nacional, aprobado por Decreto 3426/1969, de 13 de 
noviembre, no impone términos para la ejecución del plan de etapas $y$, en cualquier caso, arranca y tiene su cobertura legal no tanto en la Ley del Suelo como en la citada Ley de 1963 de Centros y Zonas de Interés Turístico Nacional.

- El artículo 20 de la Ley de 1963 establece que la vigencia de los planes de ordenación de un centro declarado de interés turístico nacional se ajustará a lo dispuesto en la Ley de Régimen del Suelo y Ordenación Urbana; en aquel momento, Ley de 12 de mayo de 1956, en cuyo artículo 36 se prevé que los planes de ordenación y los proyectos de urbanización tendrán vigencia indefinida; dicho precepto no ha sido modificado en la reforma de la Ley del Suelo de 1975, ni -obviamente- en el Texto Refundido. En el capítulo IV del título II del Reglamento de 23 de diciembre de 1964 se reitera el carácter indefinido de los planes de ordenación de los centros.

Indudablemente estamos ante argumentos de peso, y una de las soluciones a la problemática planteada podría decantarse en función del criterio que se mantenga respecto a la prevalencia de los planes sectoriales sobre los urbanísticos o viceversa.

Si la legislación de la que trae la causa el Plan de Ordenación de Riomar sigue vigente $y$ dicho plan conserva igualmente su vigencia podría fácilmente concluirse que no hay impedimento en que mediante un Estudio de Detalle se complementen ciertas prescripciones del Plan de Ordenación de Riomar, por lo que el Ayuntamiento debería proceder a la aprobación del Estudio de Detalle de iniciativa particular presentado por la mercantil ......, S. A.

No puede ser ésta nuestra posición, porque el tantas veces citado Plan de Ordenación de Riomar no es otra cosa que una suerte de plan sectorial del Estado (de indudable trascendencia urbanística, eso sí) y para nosotros el planeamiento sectorial en casos como éste debe ceder ante el planeamiento territorial o urbanístico, por modesto y transitorio que sea.

Dan luz a esta última afirmación tanto la Ley del Suelo (TR de 9 de abril de 1976) como la Ley autonómica 23/1983, de 21 de noviembre, de Política Territorial. En la primera, el artículo 180 (hoy controvertido por aspectos que aquí no vienen al caso) impone la necesidad de modificar o revisar un plan urbanístico cuando no se ajuste al mismo un determinado uso del suelo solicitado por la Administración del Estado (o autonómica), que normalmente derivará de un plan sectorial de la administración superior, lo cual denota el sometimiento de las actuaciones sectoriales al Plan Urbanístico. La segunda de las leyes citadas, en su total concepción 
y. particularmente, en su artículo 11.3, exige de los planes sectoriales su adecuación a los territoriales.

Por lo demás, no es claro que, en cuanto a la zona IV se refiere se carezca de término para acometer el llamado "programa de actuación» porque si bien el Plan de Ordenación no estableció fechas, conduciría al absurdo mantener-como se pretende por la peticionaria- que pueda prolongarse "sine die» la ejecución del Plan. Pueden servirnos al respecto como referencia las prescripciones contenidas en el Real Decreto 1374/1977, de 2 de agosto, sobre agilización en la formación y ejecución de los Planes de Urbanismo. Dicho Decreto, previa habilitación legal, estableció medidas en orden a la ejecución de los Planes de Ordenación, refiriéndose -eso sí- a Planes Parciales, Planes Especiales y Programas de Actuación Urbanística, obligando a las corporaciones locales a. fijar plazos en la ejecución de dichos planes cuando careciesen de programas de ejecución, determinando, además, que si no fuese cumplido tal mandato "se entenderá que las obras de urbanización que hayan de emprenderse en la realización del Plan deberán estar acabadas a los quince meses a partir de la entrada en vigor de este Real Decreto».

Tenemos dudas sobre la posible aplicación extensiva de este precepto a los Planes de Ordenación contemplados en la Ley de Centros y Zonas de Interés Turístico Nacional, pero es claro que el Ordenamiento Jurídico, interpretado en su conjunto y atendiendo fundamentalmente al espíritu y finalidad de las normas (art. 3.1 CC) no puede amparar interpretaciones que conducen al absurdo y que resultan contrarias al principio de justicia material. Es difícilmente mantenible que un plan nacido como clara medida de fomento (recuérdese que antes del Plan de Ordenación y como requisito previo al mismo, fue aprobado por Orden del Ministerio de Información y Turismo, de fecha 12 de abril de 1966, el Plan de Promoción Turística para Riomar) pretenda -en cuanto a la zona IV se refiere- activarse veinte años después. Con otras palabras, en estos momentos, dicho Plan, para las zonas no consolidadas, carece de causa.

El legislador catalán se ha ocupado de esta misma problemática -Planes pendientes de ejecutar- en la Ley 9/1981, de 18 de noviembre, sobre Protección de la Legalidad Urbanística así como en el Reglamento de dicha ley, aprobado por Decreto de 26 de agosto de 1982.

En la disposición transitoria primera, 1.a) y b) de la Ley, se dice:

"Las corporaciones locales, en el plazo de seis meses a partir de la entrada en vigor de esta Ley, y previa audiencia del promotor y requerimiento, en su caso, a fin de aportar 
la documentación necesaria, adoptarán, en relación con los planes parciales de iniciativa particular aprobados definitivamente que estuvieran en curso de ejecución en su término municipal, alguna de las determinaciones siguientes:

a) En el supuesto de que las obras de urbanización previstas en el plan parcial correspondiente estuviesen realizadas en un 50 por 100 o más, aprobación inicial y provisional del proyecto o de los proyectos de urbanización que comprendan las obras y servicios que en ellas falten, si no estuvieran aprobados con anterioridad, e indicación del plazo o plazos de ejecución -mediante la delimitación de polígonos, en su caso-, que no podrá ser superior a quince meses, excepto si el plan parcial contuviera un plan de etapas que previera un plazo más largo.

b) En el supuesto de que las obras de urbanización previstas en el plan parcial estuvieran ejecutadas, en menos de un 50 por 100, propuesta de modificación del plan, que consista en la reducción de su ámbito territorial, de modo que, sin perjuicio del mantenimiento de las parcelas que por el hecho de estar urbanizadas sean aptas para la edificación, sean excluidas aquellas otras cuya urbanización no se pueda garantizar que se realizará en un plazo de quince meses o más, si el plan de etapas del plan parcial así lo previera.»

En la misma disposición transitoria, apartado 2, se prevé la intervención del Departamento de Política Territorial en sustitución o subrogación de la Corporación Local.

Estos preceptos son esgrimidos en el informe de letrado que acompaña al Estudio de Detalle pretendiendo justificar la vigencia del plan de etapas contenido en el Instrumento de Ordenación de Riomar de 1969, al no haberse producido sobre el promotor ni requerimiento ni audiencia, sea del Ayuntamiento o del citado órgano autonómico.

A este equivocado razonamiento puede contestarse 10 siguiente: En primer lugar, que los preceptos de la ley autonómica se refieren a Planes Parciales, naturaleza de la que no participa el Plan de Ordenación de Riomar de 1969, y en segundo lugar, que manteniéndose la aplicabilidad de las disposiciones transitorias transcritas al repetido plan, debe coherentemente reconocerse que antes le fue de aplicación el Real Decreto 1347/1977, de 2 de junio, $y$, por tanto, según prescribe su artículo $5 .^{\circ}, 3$, las obras de urbanización debieron haberse acabado quince meses después de la entrada en vigor del mismo, es decir, el 18 de septiembre de 
1978. Es claro que en esa fecha ni se acometieron, ni mucho menos finalizaron las obras de urbanización de la zona IV, por lo que cabe concluir la extemporaneidad del Plan de Ordenación de Riomar en dicha zona a partir de esta fecha en último lugar citada.

Por lo demás, la inexistencia de requerimiento seguramente obedeció a que tanto por parte del Ayuntamiento de ....... como por el Departamento de Política Territorial y Obras Públicas se mantuviese expresa o implícitamente la posición explicada en la primera de nuestras hipótesis.

\section{INCUMPLIMIENTO DEL PLAN DE ETAPAS}

En el Estudio de Detalle se dice cumplir las etapas previstas en el Plan de Ordenación de 1969, al no establecerse términos de ejecución.

Si bien es cierto que el plan no estableció términos fijos (lo cual, dicho sea tangencialmente, demuestra la poca rigurosidad de un plan cuyo objetivo capital fue el fomento de la actividad turística en el delta del Ebro, en armonía con la concepción desarrollista a ultranza que impregna la legislación sobre Centros de Interés Turístico Nacional), es incierto que hasta ahora se haya venido respetando el plan de etapas. A este respecto en el referido Plan de Riomar se establece literalmente:

\section{«2.0 PLAN DE ETAPAS}

Por lo que se refiere al Plan de Etapas, el programa de actuación estará dividido en las siguientes cuatro etapas:

\subsection{Primera Etapa}

1. Se prepara la carretera de penetración desde La Cava para su servicio en la Ordenación General y especialmente a la zona V.

2. Se realiza la urbanización fundamental completa en la zona $\mathrm{V}$.

3. Se efectúa el viario correspondiente al paseo marítimo.

4. Realización de las urbanizaciones fundamentales a los centros comerciales y hoteleros secundarios correspondientes.

\subsection{Segunda Etapa}

1. Se completa la red viaria principal con todos sus servicios.

2. Efectuarse la urbanización fundamental completa en las zonas I, II y IV.

3. Ejecución de la urbanización fundamental de los centros comerciales, culturales y hoteleros correspondientes. 


\subsection{Tercera Etapa}

1. Se realiza la urbanización fundamental completa en las zonas III y VI.

2. Urbanización de las zonas deportivas, centros comerciales secundarios, centros culturales, de espectáculos y sanatorios correspondientes.

\subsection{Cuarta Etapa}

1. Ejecuta la urbanización fundamental completa en las zonas I y VII.

2. Se urbanizan los centros comerciales secundarios correspondientes.»

Si dentro de la primera etapa debió efectuarse el viario correspondiente al Paseo Marítimo, así como la realización de las urbanizaciones fundamentales a los centros comerciales y hoteleros secundarios correspondientes, entre tanto no se hayan realizado tales obras en su integridad (por ejemplo: urbanizado por completo el Paseo Marítimol, no puede pasarse a la segunda etapa, en la que entra la urbanización fundamental completa en las zonas I, II y IV. Entiendo que «efectuar el viario correspondiente al Paseo Marítimo" no puede consistir únicamente en abrirlo, como efectivamente ha ocurrido, sino que debe comprender la completa urbanización del Paseo, en los términos previstos ahora, por ejemplo, por el artículo 59 del Reglamento de Gestión Urbanística.

El promotor del Estudio de Detalle parece olvidar que no puede pasarse a una etapa sin haberse concluido la anterior e incurre además en algún grave error conceptual al afirmar que la urbanización del Paseo Marítimo corresponde al Ayuntamiento, cuando dicho Paseo se encuentra dentro del Plan de Ordenación, en zona marítimo-terrestre, y por ello obtuvo el promotor en su día la pertinente concesión demanial del Estado, al amparo de la entonces vigente Ley de Costas y demás normativas concordantes.

\section{OTRAS CONSIDERACIONES}

Aprobándose el Estudio de Detalle y solicitado el subsiguiente proyecto de urbanización, el Ayuntamiento de ...... sentaría un precedente administrativo de serias $y$ negativas consecuencias para el municipio; seguramente se vería compelido a dar el mismo tratamiento a todo el ámbito de aplicación del Plan originario de 1969 y permitiendo, a partir de finales de 1989, que la nada desdeñable superficie de ......Ha en pleno delta del Ebro pudiera ser urbanizada y aprovechada a efectos urbanísticos sin la ordena- 
ción integral que obras y aprovechamientos urbanísticos de tal magnitud exigen. Entendemos que la ordenación a efectos urbanísticos de tan extensa superficie no puede depender de una suerte de Plan sectorial datado veinte años atrás, sino de un Plan General de Ordenación Urbana o -como mínimo-de unas Normas Subsidiarias de Planeamiento, seguido de uno o varios Planes Parciales.

No debe olvidarse, además, que de esta manera el Ayuntamiento $-y$ en definitiva, la comunidad vecinal- podrá beneficiarse del 10 por 100 del aprovechamiento medio de cesión obligatoria y gratuita en el suelo urbanizable programado de Plan General de Ordenación Urbana o en el apto para urbanizar de Normas Subsidiarias Municipales de objeto amplio o pleno, según permite en este último caso el artículo 57 del Reglamento de Gestión Urbanística de 1978 (dando por hecho que tal clasificación en todo o en parte merezcan los terrenos no urbanizados de las zonas I a IV y VI del viejo Plan de Ordenación de Riomar).

Se lograría así que -según prevé el párrafo segundo del artículo 47 de la Constitución Española- la comunidad participe en las plusvalías que genere la acción urbanística de los entes públicos.

\section{CONCLUSIONES}

En base a todo lo antedicho, resulta de rigor concluir lo siguiente:

Primera. El Ayuntamiento de ...... debe resolver la no aprobación del Estudio de Detalle de iniciativa particular presentado por ......, S. A., y suscrito por el arquitecto $D$. ..... para la ordenación volumétrica de las edificaciones a construir en el ámbito de la isla $H$ de la Urbanización

Segunda. La desestimación de la solicitud procede, tanto si se entiende -de acuerdo con la primera de las hipótesis desarrolladas- que el Plan de Ordenación Urbana de Riomar de 1969 quedó sin validez ni efectos tras la aprobación del Proyecto de Delimitación de Suelo Urbano de ...... como si -según la segunda de las hipótesis- dicho Proyecto de Delimitación de Suelo Urbano de ...... no pudo alterar el régimen urbanístico derivado del indicado plan nacido al amparo de la legislación sectorial sobre Centros de Interés Turístico Nacional.

Tercera. Las anteriores conclusiones se circunscriben al Estudio de Detalle presentado, siendo extrapolables a cualquier otro cuyo ámbito territorial coincida total o en parte con las zonas I, II, III, IV. VI y VII del Plan de Ordenación de Riomar de. 1969. La zona $V$ participa de una problemática singularizada en relación con 
las demás, dado su grado de consolidación, la existencia de obras y servicios urbanísticos, así como su inclusión dentro del perímetro de suelo urbano aprobado mediante el PDSU de 1980, quedando el informante a disposición de la corporación para acometer, en su caso, el estudio jurídico particularizado de la misma.

Es este mi dictamen sobre el particular, que someto gustosamente a cualquier otro más fundado en Derecho.

En a 14 de noviembre de 1989

El Secretario General del Consell Comarcal

Manuel J. Domingo Zaballos

Sr. Alcalde-Presidente del Ayuntamiento de

\section{ANEXO}

\section{PROPUESTA DE RESOLUCION}

Dada cuenta del expediente incoado a instancia de ......, S. A., presentando Estudio de Detalle de su iniciativa particular para la ordenación de la isla $\mathrm{H}$ de la Urbanización

Resultando que el asunto quedó sobre la mesa en sesión plenaria habida el 7 de agosto, a resultas de que se emitiese informe jurídico,

Considerando el contenido del informe sobre el particular, suscrito en fecha 14 de noviembre $y$ obrante en el expediente administrativo, el Pleno, tras votación ordinaria y por ......

\section{ACUERDA:}

Primero: Desestimar el Estudio de Detalle presetado por D. ...... en nombre de ....., S. A., para la ordenación de la isla $H$ de la Urbanización ...... por cuanto opera sobre terrenos clasificados actualmente como no urbanizables, haber quedado sin validez el Plan de Ordenación Urbana de Riomar de 1969 en cuanto se refiere a sus zonas I, II, III, IV, VI y VII y, por lo demás, incumplir el Plan de Etapas del mismo.

Segundo: Notificar en reglamentaria forma el presente acuerdo al peticionario. 
REALA-1990, núm. 245. DOMINGO ZABALLOS, MANUEL JOSE. CENTROS DE INTERES TURISTIC...

REALA-1990, núm. 245. DOMINGO ZABALLOS, MANUEL JOSE. CENTROS DE INTERES TURISTIC... 
REALA-1990, núm. 245. DOMINGO ZABALLOS, MANUEL JOSE. CENTROS DE INTERES TURISTIC...

\section{JURISPRUDENCIA}

REALA-1990, núm. 245. DOMINGO ZABALLOS, MANUEL JOSE. CENTROS DE INTERES TURISTIC... 
REALA-1990, núm. 245. DOMINGO ZABALLOS, MANUEL JOSE. CENTROS DE INTERES TURISTIC...

REALA-1990, núm. 245. DOMINGO ZABALLOS, MANUEL JOSE. CENTROS DE INTERES TURISTIC... 